\title{
Article
}

\section{The Incompatibility of Games and Artworks}

\author{
Brock Rough*
}

Recent debate has focused on whether videogames are art. Whatever the answer, the debate has largely taken it for granted that videogames are games, and that this is unproblematic for the art status of videogames. This paper argues that something being a game is incompatible with it also being an artwork, and thus insofar as videogames are games, they cannot be artworks. This incompatibility arises out of the different attitudes that are prescribed for engaging with games versus those for engaging with artworks. Citing a modified definition of games from Bernard Suits and commonly held conditions of artworks, I show that for an artist to intend something as a game or an artwork is to intend essential constitutive conditions of the object that preclude the object from being both a game and an artwork. This requires a reconsideration of several contemporary theories about games and art while also providing an analysis of games that calls for them to be appreciated as what they are without distracting miscategorization.

Keywords: games, art, aesthetics, Suits.

Games and artworks are incompatible things. ${ }^{1}$ If something is a game, then it cannot also be an artwork and vice versa. Distinguishing between games and artworks matters for more than just an orderly taxonomy; games and artworks are judged on different metrics and appreciated by different criteria. If it turns out, as I argue, that they are incompatible things, then this argument serves as an admonishment to keep the creative and appreciative endeavors of games and artworks separate so as not to saddle them with misguided aims and concerns. I want the artworks I experience to be excellent as well as the games I play. In part what I argue for here is simply that artworks should be good qua artworks, and games qua games. To confuse the two is to court dissatisfaction because of a misidentification of the object under inquiry. ${ }^{2}$

* A version of this paper was presented at the 2015 American Society of Aesthetics meeting in Savannah, Georgia and the 2016 MAGFest convention. I want to thank the many people who have provided helpful feedback, especially Max Bialek, several anonymous referees, and the editors of this journal.

1 This conclusion is quite different from Roger Ebert's infamous assertion that videogames are not, and never can be, art (Ebert 2010). He argues that there is something about videogames, and not games, (though he is not terribly clear on this distinction) that makes them unable to be artworks. His analysis of both videogames and artworks is confused, and thus, although the conclusions of our arguments may have some extensional overlap, the reasons for them are quite different.

2 Which is not to say that the two cannot utilize features of the other, often in interesting and subtle ways. Rather, in favor of my argument, that they can do so calls for the clarification offered here between how each should be understood and appreciated. 
Making clear the distinction between games and artworks is also relevant to the current debate over the art status of videogames. Several positions have been taken, but most of them assume without argument that videogames are games and continue their arguments from there. This paper aims to show that this assumption is a mistake, and that demonstrating the incompatibility of games and artworks requires a different approach to understanding the art status of videogames, as well as debates about the art status of games in general.

Artworks and games are ontologically distinct things, but this should not be confused with the claim that the parts, elements, and pieces that make up an artwork or a game could not be put to other uses. This also does not mean that videogames, or other things that are commonly categorized as games, cannot be artworks. ${ }^{3}$ For any physical or structural object that is a constitutive part of a game or an artwork, be it physical pieces or a computer program or notes on a page or a set of rules, while they could, with the proper adjustments, be a constitutive part of either an artwork or a game (or something else), they do not wholly constitute the work that they are a part of. Games and artworks both have among their constitutive parts prescriptions for how to appropriately engage and appreciate them. ${ }^{4}$ It is these fully constituted works made up of constitutive parts, including creative intentions and prescriptions inter alia, that is the target of my argument, not solely the individual or physical parts that make them up. The position I am defending is that the ontologically complex things that are games and those that are artworks cannot be identical with each other, despite the possibility that the constitutive parts that make them up could potentially be constitutive parts of either.

Duchamp's Fountain is a paradigm example of how creative intentions can alter an object's prescriptions for how we are to engage with it to the point of changing it from one kind of object to another, namely from a quotidian object to an artwork. A urinal is not merely a physical object with a particular shape, but that physical thing along with its intended function, i.e. the prescriptions, norms, and conventions that guide our proper interactions with it. ${ }^{5}$ Similarly artworks are not merely their physical substrate, but also a collection of prescriptions, norms, and conventions. This is a particular case of the general argument given by Danto about "mere real things." ${ }^{6}$ Thus Duchamp's

3 A brief clarifying remark: I distinguish between games and videogames and avoid using the terms interchangeably, in particular the shorthand 'game' for 'videogame'. The argument that I present is for the incompatibility between artworks and games, not artworks and videogames.

4 At least those things, games in particular, that are works proper. Ad hoc games that arise only in the instances of spontaneous game-playing that generate them do not have such prescriptions antecedently. It may turn out on a robust enough notion of works that not all games are works. The argument here does not depend on this possibility turning out one way or the other, but it should be noted that games simpliciter can arise under differing, or absent, amounts of foresight.

5 For more on selection as art-making, see Levinson 2011b.

6 See Danto 1974. A similar idea can be found in Ruth Millikan’s notion of “proper function," see Millikan 1989. The important distinction is recognizing the purpose that an object has, in the case of artifacts what the object was made for, and distinguishing that from what an object can function as. While a book can serve as a 
Fountain is no longer a urinal, but an artwork partly constituted by the physical object that used to partly constitute a urinal. The functions, conventions, prescriptions, and proscriptions that the object had when it was a urinal have been altered, which is why it is no longer appropriate to have Fountain installed in a bathroom and used as a urinal. Instead it is appropriate that we consider the object for its artistic merit, otherwise the various attempts over the years to urinate into it would not be as newsworthy or interesting as they are. Nor has the art status of Fountain spread to other urinals through mere physical resemblance and similarity of what it can function as. Ordinary non-artwork urinals do not carry with them the prescription that we appreciate them for any artistic merit, for they have none. It is important that the physical object that partly constitutes Fountain used to be a urinal, but it is also important that it is no longer a urinal, understood as a more (and differently) ontologically complex collection of objects, functions, prescriptions, etc.

This way of differentiating objects in part by their functions and prescriptions allows us to sketch the difference, and incompatibility, between games and artworks. Thus I think the category we ordinarily call "videogames" (or other categories, like "computer games," "boardgames," etc.) does not map cleanly onto one of the categories of games or art. As will be seen, some videogames will turn out to actually be games (but not artworks), while others are artworks (but not games). For example, Chess is a game and, arguably, the videogame This War of Mine (11 bit studios, 2014) is an artwork. ${ }^{7}$ At the very least, it is a work of a kind that requires a kind of engagement and appreciation that requires more than merely engaging with it as a game. ${ }^{8}$ In This War of Mine, one is tasked with managing a group of survivors in an urban war zone. It presents the audience with morally difficult choices, such as whether to allow other survivors to camp in your base which might put too great a demand on your supplies or allowing a betrayer into your midst, or whether to raid the stores of nearby, equally victimized, survivors, turning your own survival actions into predation. It is a work meant to impress upon its audience the desperate and vicious effect that war has on those it impacts beyond direct combat. To "play" it "to win," to accumulate the most points, or merely survive, without consideration of the morally ambiguous aspect of the work would be to miss the point and thus to engage with it improperly. On the other hand, Chess is an abstract game with a minimal veneer of make-believe about war that extends only to giving pieces titles like "knight" and "queen." To not play it like this but to instead reflect during the game

paperweight, using it in this fashion does not make it one. Similarly, just because an object fails to function correctly (e.g. a defective heart), its historical background, including in the case of artifacts the intentions with which it was made, determine its functional identity.

7 Even if on the final analysis it turns out that This War of Mine is not an artwork, one need simply replace it with a different videogame that is an artwork.

8 The incompatibility argument presented here neither makes nor depends on the distinction between artworks and works simpliciter made in Lamarque 2010. All that is required here is only that if something is an artwork, it cannot also be a game, and vice versa. While the argument presented here, I believe, goes through even when it incorporates Lamarque's theory, there is not the space to demonstrate that here. 
on what it says about the nature of war and the state of man which wages it would be to do something inappropriate, or at least, something unnecessary to the proper engagement with it.

It also does not follow from the incompatibility of artworks and games that one can tell just from looking at an object if it is a part of a game or an artwork. Extending William Kennick's warehouse test for artworks to games, one cannot go into a warehouse of unmarked items and correctly identify all the works of art, nor could one properly identify all games. ${ }^{9}$ This is perhaps even more so the case with games than art, as many games exist only as abstract sets of rules and thus are harder (on the order of impossible) to find in a warehouse than many primarily concrete artworks. ${ }^{10}$ Barring the problem of identifying abstracta, if one were to come across what appeared to be a Chess set how would one know if it belonged to the game Chess or an artwork that had appropriated a Chess set? Clearly one could not, and one must always know more about an object than just its physical parts to properly identify it as an artwork or a game, especially since, for any given physical object, without knowing more it could be a part of either. All of this is to caution against becoming distracted from the actual target of the argument and thinking that it applies to the mere constituent objects that we often take to be a game or an artwork, and mistakenly concluding that they could never be constituents of the other.

The incompatibility of games and artworks impacts the debate over the art status of videogames. Grant Tavinor defends a positive answer in his The Art of Videogames. ${ }^{11}$ In Dominic Lopes' A Philosophy of Computer Art he suggests that videogames can be art in largely the same way as other interactive computer works. ${ }^{12}$ Aaron Smuts argues that by every definition of art, videogames count as art. ${ }^{13}$ These authors and many others, both inside and outside of philosophy, argue for various conclusions, some that videogames can be artworks, some that they cannot. ${ }^{14}$ They do not, however, address a more basic concern, that of whether games themselves can be artworks. It is an open question whether all, or even any, videogames are games, but most authors take it for granted that they are. It may turn out that some, or even many, videogames are not games proper, and thus avoid the problem of this incompatibility. The incompatibility between games and artworks however, is important for the way we think about both artworks and games, and how we think about videogames, in both their game and non-

9 This is contrary to Kennick's original claim, which is that even without a definition of art, most people could properly identify most objects of art, see Kennick 1958.

10 For example, it is unclear how one could identify the game of Tag in a warehouse.

11 Tavinor 2009

12 Lopes 2010, ch. 7

13 Smuts 2005

14 From the perspective of artworks, some have argued that artworks are games, or include game- or play-like elements, including Kant 2000, Schiller 2004, and Gadamer 1975. Their claims are more easily understood as metaphoric; regardless, the incompatibility argument applies to their arguments as well. 
game forms. If the incompatibility argument is successful, it means we must think differently and carefully about the way we create, appreciate, understand, and criticize both artworks and games, giving each its due and proper understanding as to what it is and not as something it is not, as well as theorizing about videogames differently, whether they turn out to be games or not.

In this paper I argue that games of a Suitsian type cannot be artworks, that something's being a game is incompatible with it being an artwork. ${ }^{15} \mathrm{I}$ am otherwise silent on the issue of whether videogames are in fact games, though I suspect that not all of them are, but I will argue that insofar as something is a game, it cannot be an artwork, be it a videogame or otherwise. The question then is what is it about games and artworks that makes them incompatible? I present three points of incompatibility, each arising from the required criteria of games and artworks: (1) games and artworks cannot share the same constitutive goals, (2) artworks cannot employ the arbitrary inefficiency that is required of games, and (3) the required attitude that we take towards artworks undermines the required sufficiency of the attitude that we must take towards games.

\section{Games}

Bernard Suits proposes and defends a definition of game-playing. ${ }^{16}$ In many philosophical circles, this may seem like a Herculean task, but Suits undertakes it nonetheless, and, pace Wittgenstein, succeeds quite remarkably. Suits meets Wittgenstein's challenge, taking seriously his admonition to "look and see" what makes something a game. ${ }^{17}$ As to whether he is successful, Thomas Hurka notes, "Suits has nothing like Wittgenstein's philosophical reputation, but on this topic he’s the real philosopher.”18

Suits defines game-playing:

To play a game is to attempt to achieve a specific state of affairs [prelusory goal], using only means permitted by rules [lusory means], where the rules prohibit use of more efficient in favour of less efficient means [constitutive rules], and where the rules are accepted just because they make possible such activity [lusory attitude]. ${ }^{19}$

He also offers a "portable" version: "playing a game is the voluntary attempt to overcome unnecessary obstacles.”

15 I focus on Suits' account of games because it is the most philosophically explicit, prominent, and clearly argued. It is a carefully explicative definitive, making sense of the central notion of games, while drawing and rigorously defending, a bright line between those things that are, by the account's lights, games and things merely called games.

16 Suits 2014

17 Wittgenstein 2009, Sec. 66

18 Hurka 2005, p. xv

19 Suits 2014, pp. 43 square brackets his. 
Suits' definition is not a definition of games proper, but the activity of game-playing. This can be altered to distinguish games as objects as distinct from game-playing as an activity. This requires an amendment to the lusory attitude condition, including with it a prescription that players engage the set of rules with the lusory attitude.

This modified account captures, I believe, the extension of games correctly, while giving reason to why people call other things "games" in a metaphorical sense. There is not the space to defend Suits' account at length, but a brief review will be helpful in illuminating games' incompatibilities with artworks.

\section{Prelusory Goals}

The first element of a game is the prelusory goal. This is the goal that a player aims to achieve and is a specific achievable state of affairs. It is the kind of goal that can be specified apart from the game itself, independent of the rules as a whole. In a foot race this would be crossing the finish line before all the opponents, in Chess it is checkmating the opponent's king, and in Monopoly (Darrow and Magie, 1935) it is bankrupting all the other players.

None of these ways of achieving the prelusory goal are sufficient for winning, which is the lusory goal of the game, that of achieving the prelusory goal only by the means permitted by the rules. The prelusory goal is separable from the game itself; it is some state of affairs that could be achieved outside of following all the rules of the game. Continuing the examples, a person could cross the finish line first by starting there, or tying up the other racers. In Chess one can prevent the king from moving by rearranging all the pieces as they see fit. In Monopoly one could simply take all the money and property from the other players. ${ }^{20}$

\section{Lusory Means and Constitutive Rules}

The constitutive rules of a game are, in combination with the prelusory goal, what identify each game and differentiate it from all other games, hence the term 'constitutive'. The lusory means are just those means for achieving the prelusory goal which are permitted by the rules. In a footrace, this means starting at the starting line, waiting until the gun is fired, staying on the track and in your lane, and only locomoting using your

20 The prelusory goal may not always, however, be separable from the institution of the game itself. For instance, checkmate is not a mere configuration of objects in space, but requires the conventions that dictate what moves the pieces can make and what contexts count as checkmate. What makes the prelusory goal separable is that one can still achieve the prelusory goal without following all the rules of the game. Chess serves as an excellent example of this, as learning the game often involves setting up the board, or looking at illustrations of it, in positions that do not start at the beginning, a clear abrogation of the rules, but still follow the rules from there as a way to teach certain principles. The prelusory goal, checkmating one's opponent, remains, but because some of the rules, like beginning from the starting position, have been violated, achieving this goal does not count as winning a game of chess. 
body in the prescribed fashion (no using motorcycles, for instance, though that would be faster). In Chess you can only move when it is your turn, and must move pieces in prescribed fashion. Monopoly has many rules, all of which preclude you from just scooping up all the property cards and money.

The lusory means are determined by the constitutive rules, where the rules select inefficient over efficient means for achieving the prelusory goal. Suits makes special note of this inefficiency condition for it is the selection of inefficient means that makes an activity a game rather than a technical activity.

Think of any game at random. Now identify its prelusory goal: breasting a tape, felling an opponent, or whatever. I think you will agree that the simplest, easiest, and most direct approach to achieving such a goal is always ruled out in favour of a more complex, more difficult, and more indirect approach. ${ }^{21}$

Technical activities are those we want to complete more or less as efficiently as possible. To borrow Suits' example, much of what makes golf a game rather than a technical activity is that instead of trying to achieve the goal of putting a ball in a hole in the ground by walking up to it and placing it inside, we instead start several hundred yards away and (try to) hit it with a club.

The lusory means as defined by the constitutive rules make winning possible, where it is the achieving of the prelusory goal using only the lusory means described by the constitutive rules. These rules are constitutive of the game and to not obey them is to not play the game, which is what makes that old chestnut about games true, that cheaters never win. By Suits' analysis they weren’t even playing. ${ }^{22}$

\section{Lusory Attitude}

The final condition that makes something a game is the prescription that players engage it with the lusory attitude, which is that they accept the constitutive rules and the inefficient lusory means they specify for achieving the prelusory goal, because they make such an activity possible, that activity being to try to accomplish the goal through such restricted means. This distinguishes game playing from aberrant cases, like someone being coerced by gunpoint into "playing" what would otherwise be a game, or someone merely accidentally following the rules, but their motivation is of the wrong sort. The lusory attitude also shows how something that is not a game can be treated as if it were a game. An example of this might be the game "Traffic," where someone obeys all the rules of traffic, not because they are laws aimed at balancing safety and convenience, but because they enjoy the activity of trying to reach some destination

21 Suits 2014, p. 40+

22 They are likely still engaged with a deception about their participation in the institution of the game, see Suits 2014, Ch. 4. 
within what they treat as arbitrary restrictions. Thus one could play "Traffic," which can be treated as a game, without turning the prescriptions of traffic into a game, since there is no additional prescription for them to be taken up in such a manner.

It might be objected that Suits' definition does not capture all games. This is certainly the case if we consider all the things we call "games." But Suits' definition is an explicative one that captures a paradigmatic notion of games, those of the sort that we play to win for their own sake. It also makes sense of why some things are called games in an extended metaphoric sense. In any case, Suits' definition captures a central notion of games, and, in this author's opinion, all games, that is important to distinguish from artworks for the different creative, evaluative, critical, and appreciative ways we engage with them.

\section{Art}

The incompatibility argument depends on an uncontroversial and generally accepted condition of artworks. Whatever an artwork is, whatever its meaning, and whatever the intentions of the artist, artworks are meant to be appreciated. ${ }^{23}$ Proper engagement with an artwork requires recognizing the object for what it is and attending to its relevant features. This includes obvious things like, at least parts of, the physical object that partly constitutes the artwork, when there is one, but other features of its context of creation as well, like the identity of the artist, when it was created, the history of the medium it was created in, and the intentions of the artist. ${ }^{24}$ This is just to say that there are right and wrong ways of engaging with artworks, and the right ways include paying attention to the relevant features of the work, whatever those turn out to be. For example, it is correct to appreciate a painting inter alia for its painted surface; it is incorrect, qua artwork, to appreciate a painting for how it tastes. This is not a bold claim, and, unsurprisingly, it finds general agreement in the literature.

Broad support for this condition of appreciation comes from otherwise quite different positions across the theoretical space of the philosophy of art. One example is the kind of regard expressed in historical accounts of art, including Jerrold Levinson's proper "ways of regarding”" 25 and Robert Stecker's "the set of functions standard or correctly recognized." 26 Both highlight that established modes of appreciation matter for

23 This is not to claim that there is only one particular interpretation or appreciation of a work that is correct. Rather, it is simply the claim that works are meant for appreciation.

24 By requiring attention to intention I don't mean anything as strong as the thesis that an artist's intentions fully determine the nature of a work or its meaning, only that the nature of the work and its meaning depends, at least in some part, on the fact that artworks are intentionally created objects. These considerations are part of what make for proper evaluations of artworks. There are many accounts of art that support this general claim, though the stance defended here does not require the endorsement of any particular view.

25 Levinson 2011a, p. 236

26 Stecker 1990, p. 271 
something to be properly intended as art. Ways of appreciation of this kind allow that any kind of object can be art, but not just any kind of intended function can also be an appropriate art function, or way of treating an object once it is an artwork.

Peter Lamarque also gets at this notion of appropriate appreciation in his account of the difference between a work (not necessarily an artwork) and an object that is, by Danto's locution, a "mere real thing." ${ }^{27}$ Much could be said here that would be a rehashing of Danto's point, which space prohibits, but understanding his distinction to apply to games clarifies the incompatibility. The claim is that works have essential properties that not only make it $a$ work, but make it that work. Lamarque gives special attention to two such kinds of conditions that are essential to both ways of being a work: Conditions of Production and Conditions of Reception. In short, he argues that it is important both how a work is made and how an audience receives it. ${ }^{28}$

This is in keeping with David Davies’ pragmatic constraint, that whatever our theory of art, it must respect actual practice, the way people both make and engage with art. ${ }^{29}$ This notion is also consonant with Sherri Irvin's account of artist's sanction, which "may serve to fix the boundaries of his or her work, to determine whether a particular feature is relevant to the work's interpretation, to establish in what genre the work belongs, and, in some cases, to determine whether it, qua artwork, has a particular feature or not." ${ }^{30}$

Further support can be found in Christy Mag Uidhir's claim that if art has a purpose it is "manner specific," when it has a purpose which is "essentially constituted both by an action (or state of affairs) and a manner, such that the purpose is to perform that action (or bring about that state of affairs) in that particular manner. Failure to do so constitutes a failure to satisfy/fulfill the purpose, that is, a manner specific purpose is satisfied only if the state of affairs is brought about in the prescribed manner," and that "the prescribed manner is constitutive of the purpose." ${ }^{31}$ A similar aspect is Malcolm Budd's notion that the proper understanding of a work is nondetachable from a proper experi-

27 Lamarque 2010, p. 20 and Danto 1974, Ch. 1.

28 Lamarque 2010, p. 68

29 See Davies 2004, p. 18. It might also be wondered if the methodological approach recommended by Davies is equally applicable to the actual practice of games, especially to the belief by many game designers that they are making objects that are both games and artworks. I am sympathetic to this possibility, seeing Davies as supporting a descriptivist approach to actual practices, be they about art or games. Despite this, two considerations recommend against uncritical obeisance in regards to all elements of actual practice. The first is Davies' own interpretation of the constraint, as calling only for critical reflection on the practice, not a mere parroting of it. Davies himself (believes himself to have) followed this procedure to end in what would otherwise be called a highly revisionist account of art and artworks. Secondly, it could be argued that the pragmatic constraint does not apply to all actual practices, but only to the actual practice of art, thus not applying to the practice of game-making, which is, in light of the incompatibility argument offered below, not the same practice as the art practice. I owe my thanks to an anonymous reviewer for pressing helpfully on this point.

30 Irvin 2005, pp. 315-316

31 Mag Uidhir 2009, p. 194-195 
ence of a work, as he notes of a reliable informer about the gracefulness of a work, "The reliable informer, as he perceives the work, will not just perceive the work as being graceful but will perceive the gracefulness as it is realized in the work." ${ }^{2}$

The feature of art that I am defending is minimal: an artwork is meant to be appreciated, and appreciating an artwork includes attending to all of its relevant features. ${ }^{33} \mathrm{I}$ cite these otherwise quite different positions on the nature of art to demonstrate how widespread and ecumenical the notion is of appreciation of art by means of attention to its relevant features. None of this should strike one as controversial as it is a minimal claim about what constitutes an artwork and the artist's and viewer's relationship to a work and its meaning. While much of the debate surrounding the metaphysics of artworks centers on exactly how these claims are manifested in different cases, this point about appreciation is not the one under question.

\section{An Object That Is Both an Artwork and a Game}

As a way of demonstrating the incompatibility of artworks and games, we can consider what it would mean for one object (and not just the mere physical component) to be both a game and an artwork. There are two straightforward ways in which it seems that a game could also be made into an artwork. One is that someone creates, transforms, or appropriates a game in a way that is sufficient to make it an artwork, and doing so in a way that preserves its status as a game. The other way is that someone creates, transforms, or appropriates an artwork that they also give the necessary and sufficient conditions for being a game. I take it that either scenario results in the same kind of object being created.

\section{Art Appreciation}

Beyond these two ways of the same artifact being a game and an artwork, a confusion can arise by conflating the activity of art appreciation with the object of appreciation that is the artwork itself. This confusion can happen because the activities that are game-playing and art appreciation share many similarities, such as having prescriptions, ends, and, if the artist makes their artwork in a certain way, they can both seem to require arbitrary inefficiencies in achieving those ends.

32 Budd 2003, p. 391 Emphasis his. Budd’s point is a similar one made my Frank Sibley's writings on the nature of the aesthetic as irreducibly perceptual, not graspable by logical entailments or testimony, see Sibley 1959 and Sibley 1965.

33 The use of "relevant" here is only to exclude non-relevant features, like, say, in the obvious case, the color of the backs of canvases for the evaluation of paintings or their weight or the smell of their frames.

Of course any feature could be made relevant, but this is just in keeping with the theory, as things like the medium of the work and in particular the artist's intentions, among other thing, determine which and whether features like these are relevant. 
Even if art appreciation could also be a game, this would not result in the artwork being a game. The activity of appreciating an artwork is not the same thing as the artwork itself. As the argument here is concerned with the incompatibility between games and artworks, even if it were possible for the activity of art appreciation to be a game, that would not then show that artworks were compatible with games.

It does not appear to be the case, however, that art appreciation can be a game, nor can it be a case of the activity of game-playing, because art appreciation is a technical activity and technical activities cannot be games. Recall that this is so because technical activities are activities that aim to accomplish their goals in an efficient manner, something that games don't do. This inefficiency is the characteristic feature that distinguishes game-playing from all other kinds of activities. Games prescribe that their goal, the prelusory goal, be gotten at by inefficient means. This means that, by Suit's definition, games are not a technical activity. Art appreciation, then, being a technical activity, cannot be a game.

\section{Appropriation and Repurposing}

It is likely unnecessary to state that the Mona Lisa is not a game. ${ }^{34}$ But showing that most artworks are not games is not a very difficult, nor even interesting, claim. I am making the stronger claim that no artworks are games and vice versa.

Why couldn't someone make a work out of a game, like a readymade made from a chess set, or, the more difficult case, why couldn't someone create a game that is also an artwork, or to put it otherwise, if someone did make an artwork out of a game, why would that entail that the object in question was no longer a game?

In the case of readymades, there are several examples of artworks made from objects that ceased to have their non-artwork functions once they were selected or appropriated as art. Duchamp's Fountain is perhaps the most famous case, already explained above. A different situation would arise if someone were to take a Chess set, Chess being uncontroversially a game, and put it in a gallery. Doing so changes the function of the object that is the Chess set, and it is no longer meant to be engaged with as it was before as certain new actions are prescribed and prior ones prohibited.

The Chess set example does not really address the issue at hand, however, as a Chess set itself is not a game. The game that is Chess is a set of rules, means, and ends that we are to engage in certain ways, namely with the lusory attitude. The interesting

34 Perhaps pace Walton's account of fiction and games of make-believe (see Walton 1990). Space does not allow me to address this concern in full, but in short if we read Walton's use of "game” literally, his account does not correctly capture the notion of games, and if we read it analogically or metaphorically, then no conflict arises. I would suggest that Waltonian games are of a different sort than Suitsian games, one concerned with certain practices of make-believe and the other with rules and objectives, so no conflict arises between the two, nor does something being a member of one kind of game have any bearing on its being a member of the other kind. 
case, then, is not of appropriating the paraphernalia of a game, but someone creating an object that includes the set of prescriptions that seem to satisfy the conditions for being a game and an artwork. Is there an incompatibility in cases like this? ${ }^{35}$

\section{Artworks as Games, Games as Artworks}

The case we are interested in is whether a game itself can be an artwork and vice versa. To judge this case we can consider the individual conditions that make something a game and add to them the conditions that make something an artwork and see if they are compatible. This includes the different attitudes required for games and artworks. In consideration of these conditions we can see just how games are incompatible with artworks.

Assume for reductio ad absurdum that there is an artwork that is also a game: Artwork-Game X. By hypothesis it will have all the properties of a game and all the properties of an artwork. The resulting impossibility of such an object will demonstrate the incompatibility between games and artworks.

\section{The Prelusory Goal of Artworks}

As Artwork-Game $\mathrm{X}$ is a game, it must have a prelusory goal. ${ }^{36}$ The goal that all artworks have that is as close to the lusory goal of winning a game as one might hope, is to appreciate the artwork by paying attention to its relevant features. To get the prelusory goal of any game we separate the goal from the means that are required to achieve it, isolating the final stage of appreciation of the work from the means of achieving it, namely by attending to its relevant features. Since Artwork-Game X is an artwork, its goal must be the appreciation of the artwork by attending to the features of the work. And as Artwork-Game $\mathrm{X}$ is also a game, this goal must be an achievable state of affairs separable from the means that dictate how to achieve it. Therefore, the prelusory goal of Artwork-Game $\mathrm{X}$ is appreciating Artwork-Game X.

35 This is also distinct from playings of games being parts of artworks, as can be the case in performance works. A playing of Chess in a museum does not make chess art, nor did Diego Leclery's playing of Civilization V at the 2014 Whitney Biennial turn the game you and I can play at home into an artwork.

36 A concern arises here about the plausibility of an artwork having a goal. It is not the most comfortable fit to say that just because something has a prescription to engage with it in a certain fashion that it has a goal. For the sake of argument I grant that artworks can have goals only to make the most charitable case in favor of the compatibility between artworks and games. If it turns out that artworks do not have goals, then we get the incompatibility argument for free, so to speak, as it would be obviously impossible for artworks to have a necessary feature of games and no further argument is needed. 


\section{The Constitutive Rules and Lusory Means of Artworks}

For Artwork-Game X there must be a difference between efficient means of achieving the prelusory goal and the inefficient lusory means that the constitutive rules dictate. At first glance this seems straightforward enough; the creator of $\mathrm{X}$ can make whatever rules they desire to set the lusory means of the Artwork-Game $\mathrm{X}$ in ways that are inefficient for achieving the prelusory goal. For instance, the artist could obscure elucidating elements of the work, or prescribe outlandish and time-wasting tasks to be performed while prescribing difficult to achieve goals.

\section{The Lusory Attitude of Artworks}

Artwork-Game $\mathrm{X}$ is both an artwork and a game, and proper engagement with it requires both the lusory attitude, as a game, and the artistic attitude, as an artwork.

One should be careful to avoid an overly strong reading of the lusory attitude that would make these attitudes trivially incompatible. Recall the particular language of the lusory attitude, which says that "anyone who plays a game accepts the rules of the game just because such acceptance makes possible such activity." 37 If we read the 'just' in an exclusive way, meaning that it is the only reason one can have for playing a game, then the addition of any other reason would mean that person was not actually playing a game.

This is radical autotelism, the position that games must be played always and only for their own sake, and that any other reason that a person might have for playing a game invalidates their otherwise legitimate playing of it. While this would indeed make games and artworks incompatible, this is too strong a reading of the lusory attitude and one we ought to reject as it would rule out many cases of game-playing that we should want to preserve as legitimate. For example, it would rule out that any professional athletes are actually playing games if they are also motivated by fame or fortune.

The exclusion of professional athletes as genuine players might seem acceptable if one is keen on preserving the pure nature of amateur play. There is something to be said for those who play purely for the love of the game, and this is a distinction that we ought to preserve. However, radical autotelism would also rule out more commonplace instances of game-playing that even the defender of amateur play should hesitate to discard. Suits gives the following examples of playing games for other reasons:

to decide an issue ('Let's play a hand of poker to see who goes into town for more beer'), to achieve the greatest good for the greatest number ('You know how I hate bridge, but since you need a fourth I'll play this once'), to gain approval ('Percy joined the football team because Gwendolyn fancies football players'). ${ }^{38}$ 
We should still want to say that these players are in fact playing these games, even if

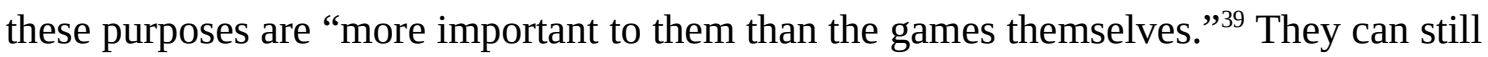
be legitimate players of these games, even if were their extra-lusory motivations removed, so would their desire to play the game.

While the lusory attitude is not always exclusive of other reasons to play a game, it must always be a sufficient attitude to allow engagement with it to count as the playing of a game. As Suits explains,

I am not committed to the position that playing a game for some further purpose somehow falsifies the proposition that a game is really being played. Nor, although extra-lusory purposes can be accomplished by playing games, is it necessary either to have or to accomplish such purposes in order to be playing a game; that is, such purposes are no part of the definition of game playing. ${ }^{40}$

While one may be motivated to play a game for other reasons, like those listed above, were they to lose those extra-lusory motivations but maintain the lusory attitude, that attitude would sufficient, along with the other conditions for gamehood, for their activity to be one of game-playing. Thus there is a way for the lusory attitude to be compatible with other reasons for playing a game. It does exclude, however, anyone who is either not motivated by the lusory attitude, or who has an attitude that prevents one from taking the lusory attitude.

\section{The Incompatibility of Artworks and Games}

Artwork-Game $\mathrm{X}$ is what is supposed to be the case when we have something that is both an artwork and a game, with all the required features. We have supposed up to this point that this is a coherent possibility. Careful examination of these conditions, however, reveals that some of them are in fact incompatible, and that no one object can be both a game and an artwork. ${ }^{41}$

38 Suits 2014, p. 154-156

39 Suits 2014, p. 155

40 Suits 2014, p. 156

41 I take a similar approach in my argument as do Christy Mag Uidhir (see Mag Uidhir 2009) and Jerrold Levinson (see Levinson 2006) in their arguments for the incompatibility of pornography and art in that I think there are incompatible features between games and art, in particular in how we are to appreciate them. Where others have argued those particular arguments fail, however, my argument differs in selecting different features of artworks on which to peg the incompatibility. In their arguments, each calls for a certain kind of regard, either too permissive or not permissive enough to accommodate the other. As will be argued, a somewhat similar incompatibility happens between games and artworks, though not one that obviously transfers to an incompatibility between artworks and things other than games, e.g. religious and political art or art and pornography. 


\section{No Separable Goal for Artworks}

The first point of incompatibility is between artworks and prelusory goals. It is a hallmark feature of games that the rules arbitrarily require inefficient means for achieving the prelusory goal. ${ }^{42}$ Their inefficiency is relative to the prelusory goal, a goal that without the imposition of the constitutive rules could be accomplished by any number of other means, each varying in degrees of efficiency. Contrary to the initial supposition the lusory means of supposed Artwork-Game X cannot exhibit these features. The goal of an artwork is to understand it, and doing this requires that we take into account all the relevant features of the work. The relevant features of the work include any feature of the work that bears on the correct appreciation of it. As the so-called lusory means of Artwork-Game X can have a bearing on the correct appreciation of the work, they count as relevant features. This means that to reach the goal of understanding a work, an audience member must take into consideration the lusory means that the artist chooses. But this means that the prelusory goal is not separable from the lusory means in the way that is required of games.

The lusory means used to achieve the supposed prelusory goal are in fact part of the prelusory goal. The prelusory goal of Artwork-Game X, namely trying to understand the work for what it is, requires consideration of the lusory means in that understanding. In other words, whatever means are allowed by the rules are also part of the target of artistic appreciation, and thus not mere means. The prelusory goal, which is the state of affairs that is meant to be separable from the lusory means, must include the means. This makes the means not merely a means to understanding the artwork, but also the target of that understanding. This creates a dilemma. The first horn is accepting that the lusory means are part of the prelusory goal, and thus the prelusory goal cannot be separated from them, preserving Artwork-Game X's artwork status but undermining its game status. The second horn is to deny that the lusory means are part of the prelusory goal, allowing them to be separable, thus preserving the game status of Artwork-Game X, but undermining its artwork status. ${ }^{43}$

42 This includes in a more complicated, but not fundamentally different, way what Suits calls open-games. These are games whose goals are to perpetuate a state, or set of states, rather than bring the activity to a close.

43 One might imagine a fast acting artist who can conjure new lusory means for reaching this understanding that allow a prelusory goal that includes the original lusory means to still be a separately achievable state of affairs. But this leads to an infinite regress, for, of course, to evaluate Artwork-Game $\mathrm{X}$ as this work, and not some other work, say Artwork-Game Y, we must include whatever lusory means are part of the work that is Artwork-Game $\mathrm{X}$. This would mean the inclusion of new lusory means forces a change of the prelusory goal to include these new means, and so on, for whatever new means the artist might devise. 


\section{No Inefficient Means for Artworks}

Related to the nature of the supposed prelusory goals of artworks, whatever means are proposed as lusory means for an artwork must fail to be inefficient. Because the goal of an artwork is to understand it, and that understanding must take into account any socalled lusory means used to reach that goal as part of the work, they cannot be an inefficient way of reaching it. In fact, they are the only means for reaching that understanding, making them exclusive of other possible means, and thus the maximally efficient, because unique, means available. While the prelusory goal of a game could be gotten at in any number of ways, the particular nature of each artwork means there is only one way of reaching the goal of understanding it, and that is through appreciating that artwork and not something else. ${ }^{44}$ It is true that there may be many ways of appreciating the artwork, but the important thing is that all of the ways are ways of appreciating that artwork and all the ways demand that the relevant features be considered. And no matter how seemingly obstructionist the artist makes the rules, obeying them is still part of appreciating that work, and thus the only way of achieving the proper appreciation of the work.

\section{The Incompatibility of Lusory and Artistic Attitudes}

A third point shows the incompatibility between games and art: a conflict between the modal conditions of the prescriptions for the lusory and artistic attitudes. Recall that the lusory attitude is necessary to game-playing while the artistic attitude is necessary to the proper engagement with an artwork. It may seem at first glance that the attitudes are compatible, that one could engage the object as a game while holding the further aim of appreciating it as art.

There are problems with this approach however. Bearing in mind that ArtworkGame $\mathrm{X}$ is supposed to be both a game and an artwork all the time, it does not alternate states from one to the other at different times. This is an ontological claim, not a psychological one. While it is certainly possible to treat something, e.g. the material component of a game or artwork, as a game at one point and then as an artwork at another point, or possibly even both simultaneously, this does not amount to the claim that treating the object in this way makes it such a thing. Thus, while it may be possible to use a game, and even playings of it as a game as component parts of an artwork, the claim being considered here is of identity between the object that is an artwork and the object that is a game. This means that the proposed object always prescribes appreciation as a game and always prescribes appreciation as an artwork and the prescriptions are con-

44 This is not the same as the claim that artworks have only one meaning. Rather it is only the claim that artworks are meant to be appreciated. There are many arguments against the former claim; the latter claim, however, is so conceptually central to the nature of artworks that it is unclear how it could be coherently denied. 
stant. So while there may be artworks that use games as part of them, and thus allow for different attitudes at different times, the proposed Artwork-Game X cannot take this approach; it requires both attitudes simultaneously. Simultaneity is required because being an artwork or a game, as with many things, means that it is appropriate to treat it as that thing whenever one engages with it. Thus more will be shown than the psychological impossibility of treating something as both an artwork and a game (if there is indeed such an impossibility); the incompatibility is a metaphysical one, not merely an epistemic one. This is an incompatibility of the prescriptions of the attitudes to be taken towards the object, not an incompatibility in the attitudes themselves per se. The prescriptions that make up games and artworks prevent the same thing from being both a game and an artwork, even if, were the prescriptions different, the same constitutive parts could make up either a game or an artwork.

Recall that the lusory attitude is not only a necessary one, but also stipulates its attitudinal sufficiency. It is always enough, attitudinally, for something to be a game that it only be engaged with the lusory attitude. With Artwork-Game X the lusory attitude is no longer a sufficient attitude for the proper engagement with it qua Artwork-Game X. Since it is also an artwork, it requires the artistic attitude. It would be inappropriate to engage with Artwork-Game X simply because one wanted to engage in the striving that the lusory means made possible, irrespective of the goal being aimed at; rather one must also engage with it because one cares about achieving the goal, which is understanding the work. These attitudes do not overlap, thus it cannot be that one is sufficient when both are necessary. ${ }^{45}$

The constancy of prescribed attitudinal engagement means that while playing a game may serve further purposes, like fitness, fortune, or fame, the reasons for playing the game must always be reasons for playing it as a game. The distinguishing feature of game-playing, and play in general, is that while it need not always be done for its own sake, it can always be done solely for its own sake. This fact makes games a paradigm case of autotelic activity. Speaking only of the formal nature of the constitutive attitudes, games prescribe the lusory attitude as attitudinally sufficient while artworks prescribe the artistic attitude as attitudinally necessary. To maintain that something can be both an artwork and a game is to hold the contradiction that in the case of any ArtworkGame X the lusory attitude is attitudinally both sufficient and not sufficient.

45 It should be noted that artworks have prescriptions, but these prescriptions hold limited power over us. While there is the prescription that we are to appreciate the artwork for the work that it is, this prescription only holds sway over our appreciative practices, not our lives in general. This makes it a conditional, and not categorical, prescription of the following nature: If we are going to properly engage with this artwork, then we must appreciate it for the work that it is. But it is not the case that at any time there is a prescription to properly engage with all artworks, unless only with the most delicate of strengths, otherwise this would be an overbearing prescription that could not be met but by the most perversely singularly minded aesthetes. 
Thus there are three points of incompatibility between artworks and games. There can be no separable prelusory goal for artworks as there must be for games; the supposed lusory means of an artwork cannot possess the necessary inefficiency for something to be a game; and the artistic and lusory attitude prescriptions are incompatible.

It might be objected that the incompatibility argument presented here rests on particular accounts of games and artworks that are too controversial, making the relevance of the argument too narrow. A brief word in defense of the modified Suitsian definition, and a defense of the application of the argument if the definition is not defensible is in order. While it is true that there are differing views on the nature of games in philosophy, Suits' view is the most philosophically rigorous and promising of the definitions of games on offer. ${ }^{46}$ And while arguments might be made for altering some of his account, ${ }^{47}$ the elements of it relevant to this discussion seem essential to any account of games that is to succeed in distinguishing games (and game-playing) from other forms of play as well as from other rule-governed activities that are properly categorized as non-games, in particular what Suits calls technical activities. To reject the elements of Suits' account on which the incompatibility rests one must reject either that games have goals, either lusory or prelusory, or deny that the means for achieving them must not be maximally efficient, or that games require an attitude like the lusory one. None of these options seems promising, as each is designed to both include paradigm cases of games and exclude obvious cases of non-games.

The account of art defended here is not an account of art proper but rather an essential feature of art, namely that artworks are meant for appreciation. I make this claim with some amount of defense from the literature, but I take it largely as a truism about art by which the entire historical and appreciative practice would dissolve if it were not the case. Certainly it is true that if either the account of games or artworks offered here were to be refuted the general claim of my argument would not hold, but neither accounts faces any devastating objections I am aware of nor is either account any more particularly controversial (in fact they are less so) than any other account on offer.

If one remains less sanguine about the Suitsian account defended here, the incompatibility argument still stands, but the lessons to be learned from it differ. Whatever it is that Suits picks out, whether a subset of games or something else, those things cannot be artworks. If one also believes that artworks can be compatible with games, where those compatibilities conflict with Suits' account should highlight promising areas of research into a competing theory of games. If one believes for independent reasons that artworks

46 For differing views on games, see Huizinga 1950, Caillois 2001, Avedon \& Sutton-Smith 1971, and explicitly contra Suits, Kolnai 1965 for a view that games involve an inherent paradox.

47 As I myself have done. To be clear, Suits does not offer a definition of games, but of game-playing. The definition of games that I defend is a modified version of Suits' account that applies to artifacts and not activities. 
are incompatible with games, where the elements of Suits' account do present an incompatibility with artworks will highlight likely areas of similar incompatibility with whatever other definition of games one finds more compelling.

\section{Game-works}

One should be careful about what the incompatibility argument does not show. It does not show that videogames cannot be artworks or that other things that seem like games cannot be artworks or that things that may appear at first glance to be artworks cannot be games. It only shows that whenever a thing is in fact a game it cannot also be an artwork and vice versa. It does not mean that the things that make up a game or make up an artwork could not, with the right adjustments, be made into the other. In particular, there is little reason, other than perhaps the history and label that includes 'game', to assume that all videogames are games. Videogames can be many things, including educational tools, simulations, toys, and interactive narrative experiences, none of which require that it also be a game. Thus, insofar as any videogame fails to be a game in the Suitsian sense outlined above, it is immune to the incompatibility argument and is at least a potential candidate for art status. Strictly speaking, the incompatibility argument allows for all videogames to be artworks, so long as none of them are games. This also holds for any other non-videogame things that might be called games, but are in fact properly intentioned to be artworks, including the things we call "boardgames," "roleplaying games," "card games," and so on.

Of course, it is likely that many, perhaps most, videogames are indeed games. In light of the incompatibility of games and artworks, theorizing about the art status of videogames as a whole must be adjusted to account for this. Furthermore, this shows the incompleteness or incorrectness of theories about the art status of videogames that assume that videogames are games. Some videogames may very well turn out to be artworks, but we must approach them with a more careful understanding of their nature.

In light of this more careful understanding, the incompatibility does not rule out the possibility of what can be called game-works. A game-work is simply a work that has features that might generally be considered the rules, means, and goals of a game's but is meant for appreciation beyond or differently from what the lusory attitude prescribes. The notion of a game-work can include videogames, board games, party games, roleplaying games, sports, or anything that resembles a game in having the apparent rules, means, and goals structure of a Suitsian game. The difference between a Suitsian game and a game-work is that game-works do not prescribe the lusory attitude, indeed cannot lest they be games, as the proper appreciation of a game-work extends beyond merely undertaking them for the striving activity they provide. 
Game-works, then, are not incompatible with being artworks, but they are not, strictly speaking, games, even though they share many qualities with games. This is because game-works are not games, despite their similarities. ${ }^{48}$ An apparent tension can arise when a game-work asks of its audience that they adopt, as part of the work, something like the lusory attitude, that the audience, at least temporarily, treat or consider the object as if it were a game before requiring it to undertake some further appreciative task. Taking such a stance is insufficient, however, for making the object a game. A game requires that we actually take the lusory attitude towards it, not that we act only as if we had that attitude, and that it is always appropriate to do so, not merely temporarily. This is similar to how assumed attitudes can fail in the other direction to make things artworks, as it is insufficient to make something an artwork merely that one considers the object as if it were an artwork. ${ }^{49}$

I suspect many videogames will turn out under investigation to be game-works rather than games, meant to be appreciated for more than just the striving activity they provide, even when such striving is part of the proper consideration of the work. This is at least the kind of videogame that is often referenced when discussions about the art status of videogames is had, that some particular work has a compelling narrative, or the gameplay makes a moral point, or it is an aesthetic triumph. All of these are characteristics that a work can be appreciated for, but they are not features that make a Suitsian game what it is. The call for this kind of appreciative approach follows straightforwardly from the incompatibility argument, resulting from the insufficiency of the lusory attitude in these cases, as these works call for more.

\section{Conclusion}

The possibility of an object being both a game and an artwork has been considered and rejected. Games and artworks are incompatible for at least three reasons: artworks being unable to have separable prelusory goals, the impossibility of inefficient lusory means, and the lusory attitude's sufficiency being undermined by the necessity of the artistic attitude. This incompatibility does not mean that a game, like most anything, could not be a constitutive element of an artwork, but a game cannot be identical with an artwork. This is important in how we critically analyze both games and artworks. This is especially the case for works that have been proposed as both games and artworks. If my argument that they are incompatible is correct, then these theories must be altered to accommodate this incompatibility and the appreciative methods these theories

48 This is similar to Gregory Currie's distinction between texts and works. see Currie 1991. While identical texts can be part of different works, so otherwise identical objects could be part of either an artwork or a game.

49 There are many cases of such temporary and merely as if attitudes asked of artworks that are not genuinely instances of the objects they merely appear to be, e.g. Roy Lichtenstein's comic strip paintings. There is a facet of the work that asks us to view the work as if it were a comic strip, but that is not the complete way of understanding the work that is prescribed of the audience. 
endorse changed in kind. Definitions and accounts of videogames must also take this fact into consideration, especially those that assume without argument that videogames are games, and analyses must be modified accordingly. Also important is that this frees the appreciation of games from the burden of having to satisfy art criteria as well. Games are excellent things, as Suits is perhaps overly enthusiastic in defending, ${ }^{50}$ and as such they should be created, engaged with, and judged on their own merits, for what they are, and not as something they are not. The incompatibility argument neither calls for antipathy towards artworks nor towards games, but instead for a clearer sense of how to create and appreciate both.

\section{Games}

11 bit studios (2014). This War of Mine. Windows.

Darrow, Charles and Magie, Elisabeth (1935). Monopoly. Hasbro.

\section{References}

Budd, M. (2003). The Acquaintance Principle. British Journal of Aesthetics, 43(4), 386-392. https://doi.org/10.1093/bjaesthetics/43.4.386

Currie, G. (1991). Work and Text. Mind, 100(3), 325-340.

https://doi.org/10.1093/mind/C.399.325

Ebert, R. (2010). Video Games Can Never Be Art. Accessed on 4/23/2013.

Hurka, T. (2005). Introduction. In The Grasshopper: Games, Life and Utopia. Broadview Press. (1978). Irvin, S. (2005). The Artist's Sanction in Contemporary Art. Journal of Aesthetics and Art Criticism, 63(4), 315-326. https://doi.org/10.1111/j.0021-8529.2005.00214.x

Kennick, W. E. (1958). Does traditional aesthetics rest on a mistake? Mind, 67(267), 317-334.

https://doi.org/10.1093/mind/LXVII.267.317

Lamarque, P. (2010). Work and Object. Oxford: Oxford University Press.

https://doi.org/10.1093/acprof:oso/9780199577460.001.0001

Levinson, J. (2006). Erotic Art and Pornographic Pictures. In Contemplating Art, (pp. 259-271). Oxford University Press. (2005).https://doi.org/10.1093/acprof:oso/9780199206179.003.0016

Levinson, J. (2011). Defining Art Historically. In Music, Art,\& Metaphysics, (pp. 3-25). Oxford University Press. (1979).

Lopes, D. M. (2010). A Philosophy of Computer Art. Routledge. Mag Uidhir, C. (2009). Why

Pornography Can't Be Art. Philosophy and Literature, 33(1), 193-203.

https://doi.org/10.1353/phl.0.0036

Smuts, A. (2005). Are Video Games Art? Contemporary Aesthetics, 2. Stecker, R. (1990). The boundaries of art. British Journal of Aesthetics, 30(3), 266-272. https://doi.org/10.1093/bjaesthetics/30.3.266

Suits, B. (2014). The Grasshopper: Games, Life and Utopia. Broadview Press, 3 ed. (1978).

Tavinor, G. (2009). The Art of Videogames. Wiley-Blackwell. https://doi.org/10.1002/9781444310177

Walton, K. L. (1990). Mimesis as Make-Believe. Cambridge: Harvard University Press.

Wittgenstein, L. (2009). Philosophical Investigations. Wiley-Blackwell, 4 ed. (1953).

Tavinor, Grant (2009). The Art of Videogames. Wiley-Blackwell.

Walton, Kendall L. (1990). Mimesis as Make-Believe. Cambridge: Harvard University Press.

Wittgenstein, Ludwig (2009). Philosophical Investigations. Wiley-Blackwell, 4 ed. (1953).

50 Suits believes that game-playing is of the highest value and the best way to spend one's time. I am inclined to agree with him that they are more valuable than they are often given credit for, but I also agree with Thomas Hurka's criticism that there are other important values as well, e.g. beauty, morality, relationships, that do not reduce to games in the way Suits might think they do. 